\title{
SISTEM INFORMASI PADA TOKO KELONTONG DIAMOND BERBASIS WEBSITE
}

\section{WEB-BASED INFORMATION SYSTEM ON DIAMOND GROCERY STORE}

\author{
Agus Budiyantara $^{1)}$ Honni $^{2)}$, Jovita Sutanto ${ }^{3)}$, Kevin Christianto ${ }^{4)}$ \\ 1) Program Studi Teknik Informatika, STMIK Widuri, Jakarta \\ ${ }^{2,3,4)}$ Program Studi Sistem Informasi, Universitas Bunda Mulia, Jakarta
}

Diterima 12 Agustus 2020 / Disetujui 19 Agustus 2020

\begin{abstract}
Diamond Grocery Store is a shop engaged in the sale of food and beverage products. This store is engaged in selling various foods, drinks and other necessities such as rice, bread, indomie, mineral water, and others. Diamond Grocery Stores still use the manual method of selling and recording supplier reports. To enhance the development of the Diamond Grocery Shop a web-based application was designed to deal with the problem. The results of the method used in the form of business processes at the store, and delivery receipts from suppliers. In making this the results obtained in the form of a web-based application to deal with problems in the Diamond Grocery Business. Based on the design of web-based applications at the Diamond Grocery Store, it was concluded that the application created has succeeded in providing a web-based application display process so that the implementation of a web-based system can greatly support business at the Diamond Grocery Store. It is hoped that this application will work well in the Diamond Grocery Store.

Keywords: Web Based, Application.
\end{abstract}

\begin{abstract}
ABSTRAK
Toko Kelontong Diamond adalah toko yang bergerak dibidang penjualan produk makanan dan minuman. Toko ini bergerak di bidang penjualan berbagai makanan, minuman dan kebutuhan lainnya seperti beras, roti, indomie, air mineral, dan lain - lain. Toko Kelontong Diamond masih menggunakan cara manual dalam menjual dan mencatat laporan - laporan barang dari supplier. Untuk meningkatkan perkembangan pada Toko Kelontong Diamond Maka dirancang Aplikasi Berbasis web untuk menangani masalah tersebut. Hasil dari metode yang di gunakan berupa proses bisnis pada toko, dan nota pengiriman dari supplier. Dalam pembuatan ini hasil yang didapat berupa aplikasi berbasis web untuk menangani masalah dalam bisnis Toko Kelontong Diamond. Berdasarkan perancangan Aplikasi berbasis web pada Toko Kelontong Diamond, diperoleh kesimpulan bahwa aplikasi yang dibuat telah berhasil memberikan proses tampilan aplikasi berbasis web sehingga dengan di terapkannya system berbasis web dapat sangat menunjang bisnis pada Toko Kelontong Diamond. Dengan dibuatnya aplikasi ini diharapkan dapat berjalan dengan baik pada Toko Kelontong Diamond.
\end{abstract}

Kata Kunci: Berbasis Web, Aplikasi.

\footnotetext{
*Korespondensi Penulis:

E-mail: agusbudiyantara@yahoo.co.id
} 


\section{PENDAHULUAN}

Perkembangan teknologi informasi saat ini sudah tidak dapat lagi terlepas dari teknologi internet di mana internet telah menjadi suatu teknologi yang tidak dapat lepas dari kehidupan manusia modern sekarang ini (Pandey et al., 2011).

Perkembangan teknologi informasi dan komunikasi pun juga memunculkan beberapa istilah baru yang berkaitan dengan dunia digital, seperti $e$-business, e-commerce, dan $e$ marketing. Huruf ' $\mathrm{e}$ ' di depan istilah-istilah tersebut mengacu pada kata electronic atau electronic network yang berarti kegiatan ekonomi tersebut menggunakan jaringan elektronik (electronic network) untuk melaksanakan kegiatan-kegiatan perniagaan atau bisnis lainnya. Istilah e-business ataupun e-commerce terkadang digunakan secara bergantian hanya untuk membedakan produk dari satu penjual atau pemasok (vendor) dengan produk dari pemasok lainnya. Pada kenyataannya, 2 semua perusahaan atau organisasi e-commerce merupakan $e$ business, namun tidak sebaliknya (Bartels, 2000; Griffin, 2013).

Aktivitas yang termasuk di dalam $e$ commerce ialah transaksi-transaksi yang terbentuk atau terjadi di Internet, Intranet, Extranet, World Wide Web, melalui email ataupun melalui faksimili (Griffin, 2013).

Berdasarkan uraian yang disampaikan di atas, penulis mendapatkan inspirasi untuk membuat website untuk membantu karyawan toko. Website yang dimaksudkan di sini adalah Toko Kelontong Diamond. Toko Kelontong Diamond adalah toko yang bergerak dibidang penjualan produk makanan dan minuman. Toko ini bergerak di bidang penjualan berbagai makanan, minuman dan kebutuhan lainnya seperti beras, roti, indomie, air mineral, dan lain - lain.

Toko Kelontong Diamond masih menggunakan sistem pemesanan dan penjualan manual dengan menggunakan catatan nota sebagai bukti sehingga terjadi kekeliruan dalam mencatat suatu laporan. Toko Kelontong Diamond hanya menjual produknya ke customer yang berkunjung dan membeli stok barang kepada supplier. Oleh karena itu dibutuhkan sebuah aplikasi yang mampu mengembangkan bisnisnya secara online.

\section{TINJAUAN PUSTAKA}

\section{A. E-commerce}

E-Commerce adalah proses bisnis yang paling digemari saat ini dan tentu saja membantu pertumbuhan ekonomi di Indonesia. E-Commerce merupakan cara organisasi untuk melakukan bisnis, mereka berupaya untuk mendorong perusahaanperusahaan publik dan swasta untuk mengadopsi e-commerce sebagai alat untuk menjadi lebih kompetitif di pasar global. Fariborzi dan Zahedifard (2012).

Perkembangan

E-commerce memberikan begitu banyak perubahan di bidang perekonomian di Indonesia. Penerapan electronic commerce (ecommerce) telah menjadikan hubungan yang erat antara produsen dan pelanggan sehingga dalam penerapan e-commerce bisa bertambah sampai ke lokasi terpencil. Ahmed dan Dalbir (2011).

\section{B. Entity Relationship Diagram (ERD)}

Database relasional didasarkan pada koleksi tabel dengan setiap tabel yang memiliki primary key - field atau fields yang nilainya unik untuk setiap baris tabel. tabel saling terkait satu sama lain dengan menempatkan primary key dari satu tabel ke dalam tabel terkait sebagai foreign key (Tegarden, Dennis \& Wixom, 2013).

\section{Visual Basic Net}

Visual Basic Net merupakan salah satu bahasa pemrograman yang dapat digunakan untuk membuat program aplikasi berbasis windows. Bahasa pemrograman ini menyediakan beberapa tool untuk otomatisasi proses pengembangan, yaitu visual tool yang 
digunakan untuk melakukan beberapa operasi pemrograman dan desain umum dan juga fasilitas-fasilitas lain yang dapat menunjang dalam pemrograman. Visual Basic merupakan bagian dari Visual Studio. Visual Basic (sering disingkat sebagai VB saja) merupakan sebuah bahasa pemrograman yang bersifat event driven dan menawarkan Integrated Development Environment (IDE) visual untuk membuat program aplikasi berbasis sistem operasi Microsoft Windows dengan menggunakan model pemrograman Common Object Model (COM). (Razaq, A 2004).

\section{METODE PENELITIAN}

Berikut ini adalah tahapan penelitian yang dilakukan dalam proses pembuatan website toko kelontong Diamond:

\section{A. System Development Life Cycle (SDLC)}

SDLC adalah proses memahami bagaimana suatu sistem informasi dapat mendukung kebutuhan bisnis dengan merancang sistem, membangunnya, dan mengirimkannya kepada user. Alan Dennis, Barbara Haley Wixom, David Tegarden (2009).

Menurut Adel Alshamrani dan Abdullah Bahattab (2015), SDLC terbagi menjadi beberapa tahap yaitu :

1. Requirement Analysis adalah fase yang menjelaskan tentang kebutuhan informasi, fungsi, perilaku, dan kinerja dari perangkat lunak melalui komunikasi antara vendor dengan pelanggan. Hasil yang didapatkan pada tahap ini adalah berupa dokumen perancangan.

2. Design adalah fase yang menjelaskan tentang dokumen perancangan yang sudah dibuat pada tahapan requirement analysis sebelum vendor mengubah persyaratan menjadi modul yang berbeda dan dapat menyiapkan tingkat dasar dari dokumen design. Output yang didapatkan adalah berupa struktur data, arsitektur perangkat lunak.

3. Coding adalah fase yang menjelaskan tentang mengembangkan rancangan yang sudah dirancang pada tahapan design ke dalam bentuk aplikasi berupa source code, basis data dan dokumentasi antar pengguna.

4. Testing adalah fase yang digunakan untuk mengembangkan tahapan sebelumnya dengan melakukan pengujian untuk memeriksa adanya kesalahan di dalam suatu aplikasi yang sudah dibuat.

5. Implementation adalah fase yang digunakan untuk menerapkan aplikasi yang sudah dirancang siap digunakan oleh pengguna secara aktual

\section{HASIL DAN PEMBAHASAN}

Berikut ini adalah hasil analisa dari pembuatan website toko kelontong Diamond.

\section{A. Requirement Analysis}

Pada tahap requirement analysis telah dilakukan analisa mengenai aktivitas yang berjalan pada sistem informasi toko melalui pembuatan activity diagram pada sistem informasi toko kelontong Diamond.

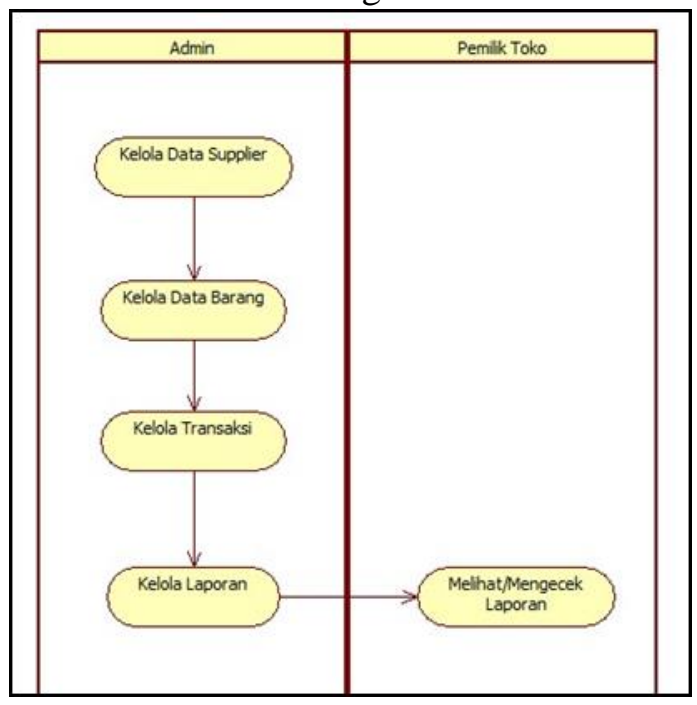

Gambar 1. Activiy Diagram

Berdasarkan pembuatan activity diagram pada gambar 1 menjelaskan mengenai bagaimana sistem informasi toko kelontong Diamond berjalan. Terdapat dua aktor yang dapat melakukan login pada website toko kelontong Diamond yaitu admin dan pemilik toko. Berikut ini merupakan penjelasan mengenai apa saja yang dilakukan kedua aktor tersebut pada sistem informasi toko kelontong Diamond: 
1. Admin berperan sebagai aktor utama yang bertanggung jawab untuk mengendalikan keseluruhan sistem. Sebelum melakukan aktivitas pada sistem, admin diharuskan untuk melakukan login terlebih dahulu. Setelah masuk pada aplikasi, terdapat beberapa fungsi yang dapat dilakukan admin pada sistem yaitu kelola data supplier, kelola data barang, kelola transaksi dan kelola laporan. Pada kelola data supplier, admin dapat melakukan input data supplier pada sistem yang dimana data supplier yang diinput akan menjadi laporan data supplier. Selain kelola data supplier, admin juga dapat melakukan kelola data barang. Data barang yang dimaksudkan adalah data barang yang dibeli ke supplier dan juga data barang yang dibeli oleh costumer di toko kelontong Diamond. Selanjutnya terdapat kelola transaksi, admin dapat juga menginput setiap transaksi yang terjadi antara toko dan supplier dan juga costumer dengan toko. Proses terakhir yang dapat dilakukan admin adalah kelola laporan. Setiap proses yang dilakukan admin sebelumnya akan disatukan dalam bentuk laporan. Laporan pada sistem terdiri dari database sistem informasi toko kelontong Diamond.

2. Beberapa laporan yang dihasilkan dari proses kelola yang dilakukan admin.

3. Pemilik toko dapat mengakses sistem informasi toko kelontong Diamond. Pemilik toko melakukan login terlebih dahulu, setelah masuk ke sistem pemilik toko memiliki akses untuk melakukan pengecekan pada setiap laporan yang dikelola admin pada sistem.

\section{B. Design}

Pada tahap ini dilakukan normalisasi pada database toko kelontong Diamond. Sehingga mendapatkan hasil relasi tabel pada sistem toko kelontong Diamond.
Relasi Tabel (ERD)

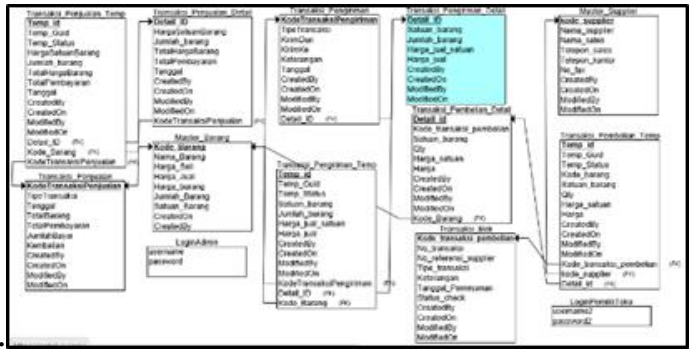

Gambar 2. Relasi Tabel (ERD)

Penjelasan pada gambar 2 merupakan relasi tabel yang terdapat pada toko kelontong Diamond. Terdapat 13 tabel adalah sebagai berikut:

a. Tabel yang pertama adalah tabel LoginAdmin yang terdiri dari attribute username sebagai primary key dan attribute password.

b. Tabel yang kedua adalah tabel LoginPemilikToko yang terdiri dari attribute username2 sebagai primary key dan attribute password2.

c. Tabel yang ketiga adalah tabel Master_Barang yang terdiri dari attribute Kode_Barang sebagai primary key kemudian diikuti dengan attribute lainnya seperti Nama_Barang, Harga_Beli,Harga_Jual, Harga_barang, Jumlah_Barang,Satuan_Barang, CreatedOn dan CreatedBy.

d. Tabel yang keempat adalah tabel Master_Supplier yang terdiri dari attribute kode_supplier sebagai primary key kemudian diikuti dengan attribute lainnya seperti Nama_supplier, Nama_sales, Telepon_sales, Telepon_kantor, No_fax, CreatedBy, CreatedOn, ModifiedBy dan ModifiedOn.

e. Tabel yang kelima adalah tabel Transaksi_Beli yang terdiri dari Kode_transaksi_pembelian sebagai primary key kemudian diikuti dengan attribute lainnya seperti No_transaksi, No_referensi_supplier, Tipe_transaksi, Keterangan, Tanggal_Pemesanan, Status_check, CreatedBy, CreatedOn, ModifiedBy, dan ModifiedOn. 
$f$. Tabel yang keenam adalah tabel Transaksi_Pembelian_Detail yang terdiri dari attribute Detail_Id sebagai primary key kemudian attribute Kode_transaksi_pembelian dan attribute Kode_Barang sebagai foreign key serta diikuti oleh attribute lainnya yaitu Satuan_barang, qty, Harga_satuan, Harga, CreatedBy, CreatedOn, ModifiedBy, dan ModifiedOn.

g. Tabel yang ketujuh adalah adalah tabel Transaksi_Pembelian_Temp yang terdiri dari Temp_id sebagai primary key kemudian attribute

Kode_transaksi_pembelian,

kode_supplier, Kode_barang dan Detail_Id sebagai foreign key serta diikuti oleh attribute lainnya Temp_Guid, Temp_Status, Satuan_barang, Qty, Harga_satuan, Harga, CreatedBy, CreatedOn, ModifiedBy dan ModifiedOn.

h. Tabel yang kedelapan adalah tabel Transaksi_Penjualan yang terdiri dari KodeTransaksiPenjualan sebagai primary key kemudian diikuti oleh attribute lainnya seperti TipeTransaksi, Tanggal, TotalBarang, TotalPembayaran, JumlahBayar, Kembalian, CreatedBy, CreatedOn, ModifiedBy dan ModifiedOn.

$i$. Tabel yang kesembilan adalah tabel Transaksi_Penjualan_Detail yang terdiri dari attribute Detail_ID sebagai primary key kemudian attribute KodeTransaksiPenjualan sebagai foreign key serta diikuti oleh attribute lainnya seperti HargaSatuanBarang, Jumlah_barang, TotalHargaBarang, TotalPembayaran, Tanggal, CreatedBy, CreatedOn, ModifiedBy dan ModifiedOn.

j. Tabel yang kesepuluh adalah tabel Transaksi_Penjualan_Temp yang terdiri dari attribute Temp_id sebagai primary key kemudian attribute KodeTransaksiPenjualan, Detail_ID, dan Kode_barang sebagai foreign key serta diikuti oleh attribute lainnya seperti Temp_Guid, Temp_Status, HargaSatuanBarang, Jumlah_barang, TotalHargaBarang, TotalPembayaran,
Tanggal, CreatedBy, CreatedOn, ModifiedBy dan ModifiedOn.

$k$. Tabel yang sebelas adalah tabel Transaksi_Pengiriman yang terdiri dari attribute KodeTransaksiPengiriman sebagai primary key kemudian diikuti oleh attribute lainnya seperti TipeTransaksi, KirimDari, KirimKe, Keterangan, Tanggal, CreatedBy, CreatedOn, ModifiedBy dan ModifiedOn.

1. Tabel yang kedua belas adalah tabel Transaksi_Pengiriman_Detail yang terdiri dari attribute Detail_ID sebagai primary key kemudian KodeTransaksiPengiriman dan Kode_barang sebagaiforeign key serta diikuti oleh attribute lainnya seperti Satuan_barang, Jumlah_barang, harga_jual_satuan, harga_jual, CreatedBy, CreatedOn, ModifiedBy dan ModifiedOn.

$\mathrm{m}$. Tabel yang ketiga belas adalah tabel Transaksi_Pengiriman_Temp yang terdiri dari attribute Temp_id sebagai primary key kemudian Detail_ID, KodeTransaksiPengiriman dan Kode_barang sebagai foreign key serta diikuti oleh attribute lainnya seperti Temp_Guid, Temp_Status, Satuan_barang, Jumlah_barang, harga_jual_satuan, harga_jual, CreatedBy, CreatedOn, ModifiedBy dan ModifiedOn.

\section{Coding}

Pada tahapan ini, pembuatan website toko kelontong Diamond menggunakan bahasa pemograman Visual Basic.Net dengan menggunakan bootstrap, javascript, jquery dan menggunakan database Sql Server Express sebagai tempat menampung data toko kelontong Diamond.

\section{Testing}

Pada tahapan ini, testing yang digunakan pada toko kelontong Diamond adalah menggunakan metode black box yang disebut sebagai User Acceptance Testing (UAT). Contohnya adalah terdapat pada tabel 1 di bawah ini. 
Tabel 1. User Acceptance Testing Modul_General

\begin{tabular}{|c|c|c|c|c|c|}
\hline No & $\begin{array}{c}\text { Use Case / } \\
\text { Test Case }\end{array}$ & $\begin{array}{c}\text { Pre- } \\
\text { Condition }\end{array}$ & Test Steps & Expected Results & Actual Results \\
\hline $\begin{array}{l}\text { MG- } \\
01\end{array}$ & $\begin{array}{l}\text { Login } \text { user } \\
\text { dengan } \\
\text { menggunakan } \\
\text { akun admin }\end{array}$ & $\begin{array}{c}\text { User } \\
\text { memerlukan } \\
\text { akun } \\
\text { terlebih } \\
\text { dahulu } \\
\text { untuk login }\end{array}$ & $\begin{array}{l}\text { 1. Membuka website } \\
\text { toko kelontong } \\
\text { diamond } \\
\text { 2. Memilih akun } \\
\text { dengan klik button } \\
\text { "login as admin" } \\
\text { 3. Input username } \\
\text { dengan "admin" } \\
\text { 4. Input password } \\
\text { dengan "admin } 123 \text { " } \\
\text { 5. Klik login button }\end{array}$ & $\begin{array}{l}\text { 1. User dapat } \\
\text { melakukan login } \\
\text { dan masuk ke } \\
\text { halaman awal yaitu } \\
\text { homepage yang } \\
\text { terdiri dari } 4 \text { side } \\
\text { bar berikut: home, } \\
\text { master data, } \\
\text { transaksi dan } \\
\text { laporan } \\
\text { 2. Modul yang } \\
\text { muncul adalah : } \\
\text { modul master data, } \\
\text { modul transaksi dan } \\
\text { modul laporan. }\end{array}$ & $\begin{array}{l}\text { Login berhasil } \\
\text { dan masuk ke } \\
\text { homepage situs } \\
\text { admin }\end{array}$ \\
\hline $\begin{array}{l}\text { MG- } \\
02\end{array}$ & $\begin{array}{l}\text { Login } \text { user } \\
\text { dengan } \\
\text { menggunakan } \\
\text { akun pemilik } \\
\text { toko }\end{array}$ & $\begin{array}{c}\text { User } \\
\text { memerlukan } \\
\text { akun } \\
\text { terlebih } \\
\text { dahulu } \\
\text { untuk login }\end{array}$ & $\begin{array}{l}\text { 1. Membuka website } \\
\text { toko kelontong } \\
\text { diamond } \\
\text { 2. Memilih akun } \\
\text { dengan klik button } \\
\text { "login as pemilik } \\
\text { toko" } \\
\text { 3. Input username } \\
\text { dengan "owner" } \\
\text { 4. Input password } \\
\text { dengan "owner123" } \\
\text { 5. Klik login button }\end{array}$ & $\begin{array}{l}\text { 1. User dapat } \\
\text { melakukan login } \\
\text { dan masuk ke } \\
\text { halaman awal yaitu } \\
\text { homepage yang } \\
\text { terdiri dari } 2 \text { side } \\
\text { bar berikut: home } \\
\text { dan modul laporan } \\
\text { 2. Modul yang } \\
\text { muncul adalah : } \\
\text { modul laporan }\end{array}$ & $\begin{array}{l}\text { Login berhasil } \\
\text { dan masuk ke } \\
\text { homepage situs } \\
\text { owner }\end{array}$ \\
\hline $\begin{array}{l}\text { MG- } \\
03\end{array}$ & $\begin{array}{l}\text { Register } \text { user } \\
\text { pada akun } \\
\text { admin } \\
\text { dengan } \\
\text { menggunakan } \\
\text { username dan } \\
\text { pass word } \\
\text { yang belum } \\
\text { pernah } \\
\text { digunakan }\end{array}$ & $\begin{array}{c}\text { User } \\
\text { melakukan } \\
\text { pendaftaran } \\
\text { terlebih } \\
\text { dahulu }\end{array}$ & $\begin{array}{l}\text { 1. Membuka website } \\
\text { toko kelontong } \\
\text { diamond } \\
\text { 2. klik button login as } \\
\text { admin } \\
\text { 3. Pilih not member? } \\
\text { Sign up } \\
\text { 4. Input username } \\
\text { yang belum pernah } \\
\text { digunakan } \\
\text { 5. Input pas sword } \\
\text { yang belum pernah } \\
\text { digunakan } \\
\text { 6. Klik register button }\end{array}$ & $\begin{array}{l}\text { 1. User dapat } \\
\text { melakukan } \\
\text { pendaftaran akun } \\
\text { sebagaiadmin } \\
\text { 2. Jika sudah } \\
\text { mendaftarkan akun, } \\
\text { maka bisa kembali } \\
\text { ke halaman login } \\
\text { dengan } \\
\text { menggunakan } \\
\text { button back to login }\end{array}$ & $\begin{array}{l}\text { Register } \\
\text { berhasil dan } \\
\text { akun bisa } \\
\text { digunakan untuk } \\
\text { login }\end{array}$ \\
\hline $\begin{array}{l}\text { MG- } \\
04\end{array}$ & $\begin{array}{c}\text { Login } \text { user } \\
\text { pada akun } \\
\text { admin } \\
\text { dengan } \\
\text { memasukkan } \\
\text { username dan } \\
\text { pass word } \\
\text { yang salah }\end{array}$ & $\begin{array}{c}\text { User } \\
\text { memerlukan } \\
\text { akun } \\
\text { terlebih } \\
\text { dahulu } \\
\text { untuk login }\end{array}$ & $\begin{array}{l}\text { 1. Membuka website } \\
\text { toko kelontong } \\
\text { diamond } \\
\text { 2. Memilih akun } \\
\text { dengan klik button } \\
\text { "login as admin" } \\
\text { 3. Input username } \\
\text { yang salah } \\
\text { 4. Input pass word } \\
\text { dengan yang salah } \\
\text { 5. Klik login button }\end{array}$ & $\begin{array}{l}\text { User tidak dapat } \\
\text { melakukan login } \\
\text { dengan } \\
\text { memasukkan } \\
\text { username dan } \\
\text { password yang } \\
\text { salah karena tidak } \\
\text { sesuaidengan } \\
\text { database }\end{array}$ & $\begin{array}{l}\text { Menampilkan } \\
\text { pesan } \\
\text { "username / } \\
\text { pass word anda } \\
\text { salah }\end{array}$ \\
\hline
\end{tabular}




\begin{tabular}{|c|c|c|c|c|c|}
\hline No & $\begin{array}{l}\text { Use Case / } \\
\text { Test Case }\end{array}$ & $\begin{array}{c}\text { Pre- } \\
\text { Condition }\end{array}$ & Test Steps & Expected Results & Actual Results \\
\hline $\begin{array}{l}\text { MG- } \\
05\end{array}$ & $\begin{array}{l}\text { Login user } \\
\text { pada akun } \\
\text { admin } \\
\text { dengan tidak } \\
\text { memasukkan } \\
\text { username dan } \\
\text { pass word }\end{array}$ & $\begin{array}{c}\text { User } \\
\text { memerlukan } \\
\text { akun } \\
\text { terlebih } \\
\text { dahulu } \\
\text { untuk login }\end{array}$ & $\begin{array}{l}\text { 1. Membuka website } \\
\text { toko kelontong } \\
\text { diamond } \\
\text { 2. Memilih akun } \\
\text { dengan klik button } \\
\text { "login as admin" } \\
\text { 3. Klik login button }\end{array}$ & $\begin{array}{l}\text { User tidak dapat } \\
\text { login dengan } \\
\text { memasukkan } \\
\text { username dan } \\
\text { password }\end{array}$ & $\begin{array}{l}\text { Menampilkan } \\
\text { pesan } \\
\text { "Username is } \\
\text { Required dan } \\
\text { Pass word is } \\
\text { Required" }\end{array}$ \\
\hline $\begin{array}{l}\text { MG- } \\
06\end{array}$ & $\begin{array}{l}\text { Register } u s e r \\
\text { pada akun } \\
\text { admin } \\
\text { dengan } \\
\text { menggunakan } \\
\text { username dan } \\
\text { password } \\
\text { yang pernah } \\
\text { digunakan }\end{array}$ & $\begin{array}{c}\text { User } \\
\text { melakukan } \\
\text { pendaftaran } \\
\text { terlebih } \\
\text { dahulu }\end{array}$ & $\begin{array}{l}\text { 1. Membuka website } \\
\text { toko kelontong } \\
\text { diamond } \\
\text { 2. klik button login as } \\
\text { admin } \\
\text { 3. Pilih not member? } \\
\text { Sign up } \\
\text { 4. Input username } \\
\text { yang sudah pernah } \\
\text { digunakan } \\
\text { 5. Input pass word } \\
\text { yang sudah pernah } \\
\text { digunakan } \\
\text { 6. Klik register button }\end{array}$ & $\begin{array}{l}\text { User tidak dapat } \\
\text { melakukan } \\
\text { pendaftaran akun } \\
\text { sebagaiadmin } \\
\text { karena sudah ada di } \\
\text { dalam database }\end{array}$ & Register gagal \\
\hline $\begin{array}{l}\text { MG- } \\
07\end{array}$ & $\begin{array}{l}\text { Register } \text { user } \\
\text { pada akun } \\
\text { admin } \\
\text { dengan tidak } \\
\text { memasukkan } \\
\text { username dan } \\
\text { pass word }\end{array}$ & $\begin{array}{c}\text { User } \\
\text { melakukan } \\
\text { pendaftaran } \\
\text { terlebih } \\
\text { dahulu }\end{array}$ & $\begin{array}{l}\text { 1. Membuka website } \\
\text { toko kelontong } \\
\text { diamond } \\
\text { 2. klik button login as } \\
\text { admin } \\
\text { 3. Pilih not member? } \\
\text { Sign up } \\
\text { 4. Klik register button }\end{array}$ & $\begin{array}{l}\text { User tidak dapat } \\
\text { melakukan } \\
\text { pendaftaran akun } \\
\text { sebagaiadmin } \\
\text { karena tidak } \\
\text { menginput } \\
\text { username dan } \\
\text { password }\end{array}$ & $\begin{array}{l}\text { Menampilkan } \\
\text { pesan } \\
\text { "username } \\
\text { cannot be empty } \\
\text { dan pass word } \\
\text { cannot be } \\
\text { empty" }\end{array}$ \\
\hline $\begin{array}{l}\text { MG- } \\
08\end{array}$ & $\begin{array}{c}\text { Login } \text { user } \\
\text { pada akun } \\
\text { pemilik toko } \\
\text { dengan tidak } \\
\text { memasukkan } \\
\text { username dan } \\
\text { pass word }\end{array}$ & $\begin{array}{c}\text { User } \\
\text { memerlukan } \\
\text { akun } \\
\text { terlebih } \\
\text { dahulu } \\
\text { untuk login }\end{array}$ & $\begin{array}{l}\text { 1. Membuka website } \\
\text { toko kelontong } \\
\text { diamond } \\
\text { 2. Memilih akun } \\
\text { dengan klik button } \\
\text { "login as pemilik } \\
\text { toko" } \\
\text { 3. Klik login button }\end{array}$ & $\begin{array}{l}\text { User tidak dapat } \\
\text { melakukan login } \\
\text { sebagaiowner } \\
\text { karena tidak } \\
\text { menginput } \\
\text { username dan } \\
\text { password }\end{array}$ & $\begin{array}{l}\text { Menampilkan } \\
\text { pesan } \\
\text { "username } \\
\text { cannot be empty } \\
\text { dan pass word } \\
\text { cannot be } \\
\text { empty" }\end{array}$ \\
\hline $\begin{array}{l}\text { MG- } \\
09\end{array}$ & $\begin{array}{l}\text { Login } \text { user } \\
\text { pada akun } \\
\text { pemilik toko } \\
\text { dengan } \\
\text { memasukkan } \\
\text { username dan } \\
\text { pass word } \\
\text { yang salah }\end{array}$ & $\begin{array}{c}\text { User } \\
\text { memerlukan } \\
\text { akun } \\
\text { terlebih } \\
\text { dahulu } \\
\text { untuk login }\end{array}$ & $\begin{array}{l}\text { 1. Membuka website } \\
\text { toko kelontong } \\
\text { diamond } \\
\text { 2. Memilih akun } \\
\text { dengan klik button } \\
\text { "login as pemilik } \\
\text { toko" } \\
\text { 3. Input username } \\
\text { yang salah } \\
\text { 4. Input pas sword } \\
\text { yang salah } \\
\text { 5. Klik login button }\end{array}$ & $\begin{array}{l}\text { User tidak dapat } \\
\text { melakukan login } \\
\text { sebagaiowner } \\
\text { karena } \\
\text { memasukkan } \\
\text { username dan } \\
\text { password yang } \\
\text { salah }\end{array}$ & $\begin{array}{l}\text { Menampilkan } \\
\text { pesan } \\
\text { "username / } \\
\text { pass word anda } \\
\text { salah }\end{array}$ \\
\hline
\end{tabular}




\section{E. Implementation}

Tahap terakhir adalah implementasi. Berikut ini merupakan sebagian tampilan yang ada pada website yang terdiri dari halaman login admin dan halaman laporan pembelian barang detail.

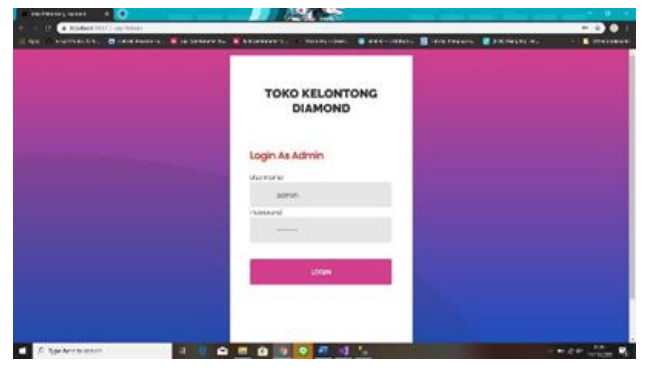

Gambar 3. Tampilan Halaman Login Admin

Pada gambar 3 merupakan tampilan dari halaman login sebagai admin. Tampilan login dari pemilik toko juga serupa namun memiliki keterbedaan pada keterangan di tampilan yaitu login as pemilik toko. Baik admin maupun user harus melakukan input username dan password terlebih dahulu untuk bisa masuk ke halaman utama website.

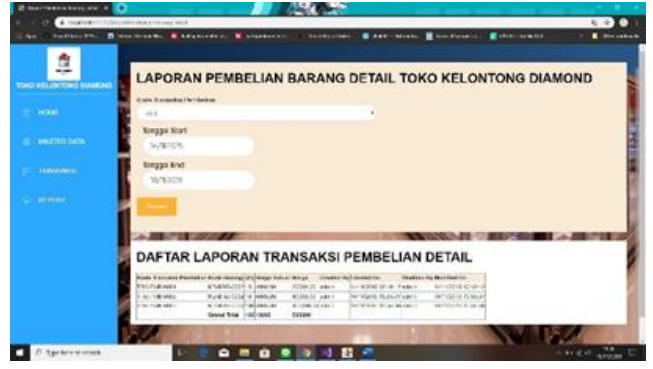

Gambar 4. Tampilan Halaman laporan pembelian barang

Pada gambar 4 merupakan laporan pembelian barang. Pada tampilan halaman laporan pembelian barang detail terdapat informasi mengenai barang yang telah dibeli oleh admin. Menu laporan barang detail dihasilkan dari proses kelola yang dilakukan oleh admin setiap kali melakukan proses pembelian barang dari supplier.

\section{KESIMPULAN}

Berdasarkan perancangan aplikasi berbasis web pada toko Kelontong Diamond, maka diperoleh kesimpulan sebagai berikut:
1. Aplikasi yang telah dibuat berhasil memberikan proses tampilan sistem berbasis web sehingga pencatatan tidak usah menggunakan buku.

2. Proses transaksi yang dilakukan tercatat secara akurat, jika terjadi kesalahan pengetikan dapat diubah.

3. Proses masuknya stok barang dan keluarnya stok barang juga tercatat secara otomatis.

4. Aplikasi yang dibuat menghasilkan semua laporan-laporan yang dapat dilihat langsung oleh pemilik toko.

5. Aplikasi yang dibuat juga memiliki data-data supplier yang menyetok barang pada toko secara otomatis.

\section{DAFTAR PUSTAKA}

Adel Alshamrani, Abdullah Bahattab., (2015). "A Comparison Between Three SDLC Models Waterfall Model, Spiral Model, and Incremental/Iterative Model", IJCSI International Journal of Computer Science Issues, Volume 12, Issue 1, No 1

Ahmed, A. A., \& S, Dalbir., (2011). Potential ECommerce Adoption Strategies For Libyan Organization. International Journal of Information and Communication Technology Research, 1 (7).

Fariborzi, E. \& Zahedifard, M. (2012). E-mail Marketing: Advantages, Disadvantages and Improving Techniques. International Journal of e-Education, e-Business, eManagement and $e$ - Learning, 2(3).

Pandey R., Dwivedi S. (2011). Ontology Description Using Owl To Support SemanticWebApplication..International Journal Of Computer.

Razaq, A (2004), Mudah Cepat Lancar Visual Basic 6.0, Yogyakarta.

Tegarden David, Alan Dennis, Barbara Haley Wixom (2013). Systems Analysis and Design with UML. John Wiley \& Sons Singapore Pte. Ltd.

Widodo \& Herlawati (2011) Menggunakan UML, Unified Modeling Language 